\title{
ORIGINAL RESEARCH \\ The Depth of the Olfactory Sulcus Is an Indicator of Congenital Anosmia
}

C. Huart

T. Meusel

J. Gerber

T. Duprez

P. Rombaux

T. Hummel
BACKGROUND AND PURPOSE: In congenital anosmia, the OB and OT can be aplastic or hypoplastic. In clinical routine, these are sometimes difficult to assess. We thus wanted to investigate morphologic differences of the OS in patients with IA since birth or early childhood in comparison with controls, to investigate whether there is a depth of OS that is predictive of IA.

MATERIALS AND METHODS: Within the context of a 2-center study, we investigated 36 patients with IA in comparison with 70 controls. MR imaging was performed with a standard quadrature head coil (1.5T; T1- and T2-weighted spin-echo sequences were used on the coronal plane). We assessed the depth of OS in the PPTE.

RESULTS: Looking at the depth of the OS in the PPTE, we found that patients with IA had a significantly smaller OS compared with controls $(P<.001)$. None of the healthy controls exhibited a depth of $<8 \mathrm{~mm}$. In patients with $\mathrm{IA}, 10$ had an OS deeper than $8 \mathrm{~mm}$, while 26 had an OS smaller than $8 \mathrm{~mm}$. Thus, a depth of the OS less than $8 \mathrm{~mm}$ clearly indicates IA, with a specificity of 1 and a sensitivity of 0.72 .

concLusIONS: In IA, the depth of the OS in the PPTE is a useful clinical indicator. Indeed, if it is $\leq 8$ $\mathrm{mm}$, it clearly indicates IA, with a specificity of 1 .

ABBREVIATIONS: ANOVA $=$ analysis of variance; FSE $=$ fast spin-echo; $\mid \mathrm{A}=$ isolated anosmia; $\mathrm{OB}=$ olfactory bulb; OS = olfactory sulcus; $\mathrm{OT}=$ olfactory tract; PPTE = plane of the posterior tangent through the eyeballs; SEM = standard error of the mean
A nosmia since birth or early childhood is a condition that can be divided into anosmias associated with chromosomal disorders (eg, Kallmann syndrome ${ }^{1}$ and Klinefelter syndrome $^{2,3}$ ) or anosmias without evidence of other defects (IA since birth or early childhood, termed "IA" throughout this article). While the underlying pathophysiology is relatively well-investigated in Kallmann syndrome, ${ }^{4,5}$ IA has received far less attention, though from the literature and our own clinical experience, IA appears to be more frequent than Kallmann syndrome. ${ }^{6-9}$

MR imaging is the technique of choice for the evaluation of the olfactory apparatus (OB, OT, and OS) in cases of suspected congenital anosmia.

In IA and in Kallmann syndrome, we know from the literature that the OB and OT can be aplastic, hypoplastic, or possibly even normoplastic. ${ }^{10-12}$ The length and depth of the OS in IA have been studied by Abolmaali et al. ${ }^{13}$ This study compared frontobasal structures of patients with IA and those of control subjects. It pointed out that the depth of the OS at the level of the PPTE reflects the presence of OBs and OTs and that there was a significant difference between the depth of the OS of controls and patients. However, measurements were not significantly different when the maximum values of the depth of the OS or its length were taken into consideration.

This finding is of major clinical value because the OBs and

Received October 25, 2010; accepted after revision March 2, 2011.

From the Department of Otorhinolaryngology (C.H., P.R.), Institute of Neurosciences (C.H., P.R.), and Department of Radiology and Medical Imaging (T.D.), Université Catholique de Louvain, Brussels, Belgium; and Departments of Otorhinolaryngology (T.M., T.H.) and Neuroradiology (J.G.), Technical University of Dresden Medical School, Dresden, Germany.

Please address correspondence to Caroline Huart, MD, Department of Otorhinolaryngology, Université Catholique de Louvain, Cliniques Universitaires Saint-Luc, Avenue Hippocrate 10-1200 Bruxelles, Belgium; e-mail: caroline.huart@uclouvain.be

http://dx.doi.org/10.3174/ajnr.A2632
OTs are often difficult to measure in daily routine, whereas the depth of the OS in the PPTE can easily be performed in axial and coronal planes by using standard techniques. ${ }^{13}$ Thus, this finding can be considered a relevant tool in the evaluation of IA.

The intention of the present study was to reinvestigate differences between the OS in patients with IA and controls; we took advantage of the fact that a larger group of subjects was available in 2 centers. Indeed, the sample of patients in the study of Abolmaali et al ${ }^{13}$ was relatively small (16 patients and 8 controls). In addition, in our clinical practice, we sometimes think that the proposed difference of an 8-mm OS depth in the PPTE between osmic and anosmic patients does not always discriminate between the 2 populations. Thus, in the present study, we wanted to reinvestigate the sensitivity and specificity of the measurement of the depth of the OS in the PPTE in a larger group of subjects, to see if there is a depth of OS that is predictive of IA.

\section{Materials and Methods}

\section{Participants}

A total of 106 subjects participated in the study (mean age, 36.5 years; range, 7-79 years; 60 females, 46 males). They were referred to the Department of Otorhinolaryngology at the University of Dresden and the University of Louvain by other departments of these Universities (eg, Pediatrics and Neurology), or they presented themselves to the smell dysfunction clinic of the respective Departments of Otorhinolaryngology. All subjects were in good health with no signs or symptoms except for anosmia, and on careful questioning, none of these patients could remember any odorous sensations apart from intranasal ones mediated by the trigeminal nerves. ${ }^{14-16}$ None had any major cranial malformation as verified by $\mathrm{T} 1$ - and $\mathrm{T} 2$-weighted sequences of the whole brain. Anosmia or normosmia, respectively, was ascer- 




Fig 1. Coronal T2-weighted 2-mm-thick view by using FSE in a control subject. It shows how to measure the OS depth in the PPTE plane. A straight line tangent to the top surfaces of gyrus rectus and medial orbital gyrus is drawn; the depth of the OS is measured by drawing the most perpendicular line possible connecting this tangent line to the deepest point of the OS.

tained psychophysically by using "Sniffin Sticks" (Burgher-Messtechnik, Wedel, Germany). ${ }^{17,18}$ In addition to psychophysical testing, most subjects with anosmia-whenever deemed necessary—also received electrophysiologic testing by using chemosensory event - related potentials ${ }^{19}$; none of the tested patients with IA had electrophysiologic responses to olfactory stimuli.

We were able to perform MR imaging in 36 patients with IA (24 females, 12 males; age range, 7-79 years; mean age, 38 years). The results were compared with those of 70 controls ( 36 females, 34 males; age range, 7-72 years; mean age, 36.5 years). Neither age nor sex distribution was significantly different between the 2 groups. Investigations were approved by the respective institutional review boards; written informed consent was obtained by all subjects.

\section{MR Imaging}

In Brussels, participants were examined on a 1.5T MR imaging system (Signa EchoSpeed; GE Healthcare, Milwaukee, Wisconsin) by using a standardized protocol including the following: 1) a 5-mm-thick standard T2-weighted FSE image (TR, $2352 \mathrm{~ms}$; TE, $80 \mathrm{~ms}$ ) covering the whole brain to rule out any organic brain disorder; 2) 5-mm-thick standard FSE fluid-attenuated inversion recovery images (TR, 10000 $\mathrm{ms}$; TE, $12 \mathrm{~ms}$; TI, $2800 \mathrm{~ms}$ ) covering the whole brain and 5-mm-thick T2-weighted gradient-echo images by using the echo-planar imaging technique (TR, $1465 \mathrm{~ms}$; TE, $16 \mathrm{~ms}$; echo-planar imaging factor) covering the whole brain to rule out the presence of any parenchymal or meningeal deposit; and 3) 2-mm-thick T1- and T2-weighted FSE images in the coronal plane covering the anterior and middle segments of the base of the skull. The coronal T1-weighted FSE sequence was

\begin{tabular}{lllll}
\hline \multicolumn{2}{l}{ Descriptive statistics of OS } & & & \\
& $\begin{array}{c}\text { Minimum } \\
(\mathrm{mm})\end{array}$ & $\begin{array}{c}\text { Maximum } \\
(\mathrm{mm})\end{array}$ & $\begin{array}{c}\text { Mean } \\
(\mathrm{mm})\end{array}$ & SEM \\
\hline Controls $(n=70)$ & 7 & 72 & 36 & 17.6 \\
Age (yr) & 8.4 & 28.8 & 13.4 & 4.1 \\
Right OS depth at PPTE & 7.0 & 24.4 & 12.4 & 3.4 \\
Left OS depth at PPTE & 8.4 & 28.8 & 13.7 & 4.1 \\
Best OS depth at PPTE & & & & \\
Patients with IA ( $n=36)$ & 7 & 79 & 38 & 18.4 \\
Age (yr) & 0.0 & 10.6 & 5.5 & 3.4 \\
Right OS depth at PPTE & 0.0 & 11.0 & 5.3 & 3.4 \\
Left OS depth at PPTE & 0.0 & 11.0 & 6.1 & 3.6 \\
Best OS depth at PPTE & & & & \\
\hline
\end{tabular}



Fig 2. Average OS depth in PPTE in patients with IA compared with that of healthy controls (95\% confidence interval). The OS depth is significantly deeper in controls than in patients with IA.

performed with the following parameters: TR, $666 \mathrm{~ms}$; TE, $10 \mathrm{~ms}$; section thickness, $2 \mathrm{~mm}$ without intersection gap; FOV, $170 \times 136$ $\mathrm{mm}^{2}$; matrix, $288 \times 184$ resulting in a voxel size of $2 \times 0.59 \times 0.74$ $\mathrm{mm}^{3}$. The coronal T2-weighted FSE sequence was performed with the following parameters: TR, $1737 \mathrm{~ms}$; TE, $90 \mathrm{~ms}$; section thickness, 2 $\mathrm{mm}$ without intersection gap; FOV, $170 \times 136 \mathrm{~mm}^{2}$; matrix, $376 \times$ 299 resulting in a voxel size of $2 \times 0.45 \times 0.45 \mathrm{~mm}^{3}$.

In Dresden, MR imaging was also performed by using a $1.5 \mathrm{~T}$ system (Magnetom Vision; Siemens Medical Systems, Erlangen, Germany) with a standard quadrature head coil. A coronal T1-weighted spin-echo sequence was performed with the following parameters: TR, $600 \mathrm{~ms}$; TE, $20 \mathrm{~ms}$; section thickness, 3-mm contiguous sections; FOV, $220 \times 200 \mathrm{~mm}^{2}$; matrix, $512 \times 512$, resulting in a voxel size of $3 \times 0.39 \times 0.43 \mathrm{~mm}^{3}$. This was followed by a T1-weighted 3D gradient-echo sequence (magnetization-prepared rapid acquisition of gradient echo) with the following parameters: TR, $9.7 \mathrm{~ms}$; TE, $4 \mathrm{~ms}$; flip angle, $12^{\circ}$ with isotropic voxels $\left(1.0 \times 1.0 \times 1.0 \mathrm{~mm}^{3}\right)$; and a T2weighted FSE sequence in the coronal plane covering the anterior and middle segments of the base of the skull with the following parameters: TR, $4800 \mathrm{~ms}$; TE, $152 \mathrm{~ms}$; section thickness, $2 \mathrm{~mm}$; gap, $0.4 \mathrm{~mm}$; FOV, $128 \times 128 \mathrm{~mm}^{2}$; matrix, $256 \times 256$; resulting in a voxel size of $2.4 \times 0.5 \times 0.5 \mathrm{~mm}^{3}$.

\section{Data Analyses}

Although the parameters for MR imaging were different between the 2 sites, this was deemed not to be of high significance because the primary outcome measure of the study was simply the depth of the OS in the PPTE. It was calculated by using the following procedure: The observer browsed the coronal T2-weighted sections from anterior to posterior and selected the first section on which the eyeball was no longer seen. This section location typically corresponded to the socalled PPTE, which cuts the anterior midsegment of the OB. ${ }^{13,20}$ Here a straight line tangent to the surface of the top of the gyrus rectus and to that of the orbital gyrus was drawn by using the electronic cursor. The depth of the OS (expressed in millimeters) was measured by drawing a perpendicular line connecting this tangent line to the deepest point of the sulcus (Fig 1). 

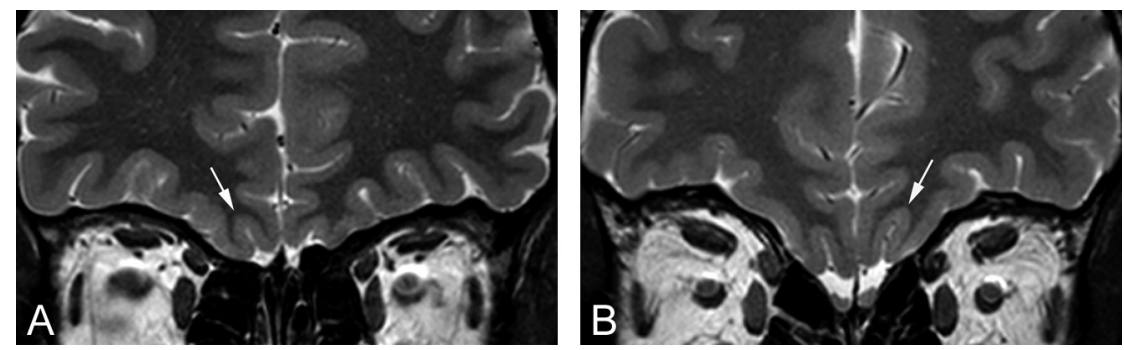

Fig 3. Coronal T2-weighted 2-mm-thick views by using FSE. The figures show a comparison between the deepest OS (white arrow) in the PPTE plane in a patient with IA (A) and a control subject $(B)$.

\section{Statistical Analyses}

Data were analyzed by using the Statistical Package for the Social Sciences, Version 17.0 for Windows (SPSS, Chicago, Illinois). For comparisons between groups of patients, we used an ANOVA (within-subject factor was "side"; the between-subject factor was "group") and an independent-samples $t$ test. The $d f$ was adjusted according to Greenhouse-Geisser. The $\alpha$ level was set at 05 .

\section{Results}

Descriptive statistics of the measures of the depth of OS in the PPTE are given in the Table. An ANOVA procedure was used to confirm that both groups were equivalent in terms of age and sex (age, $P=.79$; sex, $P=.14$ ). Results also indicated that patients with IA have significantly smaller OSs compared with controls, both for the left and the right sides $(t>10.4, P<$ .001) (Fig 2). This was also true when comparing depths of the respective deepest OSs between patients and controls $(t>9.8$, $P<.001$ ) (Fig 3).

When looking only at the respective deepest OS in the PPTE, we found that none of the healthy controls exhibited a depth lower than $8 \mathrm{~mm}$. In patients with IA, however, 10 had a depth of the OS in the PPTE deeper than $8 \mathrm{~mm}$, while 26 patients with IA exhibited a depth of the OS smaller than 8 $\mathrm{mm}$. This observation resulted in a specificity of 1 (compare with Abolmaali et $\mathrm{al}^{13}$ ) with a sensitivity of 0.72 . In other words, if the depth of the OS in the PPTE is $\leq 8 \mathrm{~mm}$, subjects exhibit IA; if the OS is deeper, this measure does not clearly predict IA.

\section{Discussion}

In congenital anosmia, the length and depth of the OS have been reported by others to be aplastic, hypoplastic, or possibly even normal..$^{9-11,19,21}$ In the present study, consistent differences between the depth of the OS in patients with IA and controls were only found when measurements of these were performed in the PPTE.

Results from the present investigation thus suggest that the depth of the OS in the PPTE is a useful clinical indicator of IA. Indeed, if the depth of the OS in the PPTE is $\leq 8 \mathrm{~mm}$, it clearly indicates IA with a specificity of 1 . If it is deeper, the measure does not clearly predict IA.

A previous study compared the depth of the OS in IA and controls. ${ }^{13}$ It noted depths of the OS in IA of 5.0 \pm 3.3 and $6.4 \pm 3.4 \mathrm{~mm}$, respectively, for the left and right sides, whereas in controls, these measurements were, respectively, $8.8 \pm 1.5$ and $8.9 \pm 1.4 \mathrm{~mm}$, with a significant difference. In addition, it showed differences among the patients with IA, separating those with nonvisible OTs, which had a depth of the OS of $<4$ $\mathrm{mm}$, and those with visible olfactory tracts, which had a depth of the OS of $>4 \mathrm{~mm}$ in the PPTE, and no overlap between both groups in terms of the depth of the OS. This study thus showed that the depth of the OS in the PPTE reflects the presence of OTs and is useful in the diagnosis of IA. ${ }^{13}$

Taking advantage of a large number of patients and controls, we concluded that a depth of OS of $\leq 8 \mathrm{~mm}$ clearly indicates IA ( specificity $=1$ ). This finding is useful in daily routine because the OSs are clearly visualized in axial and coronal planes with standard techniques, while OBs and OTs are sometimes hard to identify, mostly due to movement disorders.

In addition, we know from embryology that the depth of the OS is linked to the overall development of the olfactory system. Specifically, it develops in concert with the projections of the OT from the OB to the olfactory cortex. ${ }^{22}$ It might be hypothesized that modification in the sensory input to the brain could lead to changes in the morphologic development in certain brain structures. This statement was indirectly proved by a study of Hummel et al (2003), ${ }^{23}$ in which it was demonstrated that the depth of OS in the PPTE was related to overall olfactory function in healthy subjects. These speculations indicate, at least in part, that the presence or absence of sensory input leads to structural changes at the level of the central nervous system. Such morphologic consequences of missing sensory input have been demonstrated for other sensory modalities (vision, ${ }^{24}$ audition, ${ }^{25,26}$ or the somatosensory system $^{27}$ ) when sensory deprivation is present during critical periods of development. In the olfactory system, it is also well known that olfactory deprivation due, for example, to a sinonasal disease leads to a decreased volume of the olfactory bulb. ${ }^{28}$ However, no such study exists for the OS in humans.

\section{Conclusions}

The present study indicates that patients with IA have a significantly smaller OS compared with controls. The depth of the OS in the PPTE is a useful tool for the diagnosis of IA. Indeed, on the basis of the current data, a depth of $\leq 8 \mathrm{~mm}$ clearly indicates IA. Due to the ease in measuring the depth of the OS on MR imaging with standard techniques, its measurement should thus be considered as a standard in the evaluation of IA.

\section{References}

1. Kallmann FJ, Schoenfeld WA, Barrera SE. The genetic aspects of primary eunuchoidism. Am J Ment Defic 1944;48:203-36

2. Pawlowitzki IH, Diekstall P, Schadel A, et al. Estimating frequency of Kallmann 
syndrome among hypogonadic and among anosmic patients. Am J Med Genet 1987;26:473-79

3. Hazard J, Rozenberg I, Perlemuter L, et al. Gonadotropin responses to low dose pulsatile administration of GnRH in a case of anosmia with hypogonadotropic hypogonadism associated with gonadal dysgenesis $47 \mathrm{XXY}$. Acta Endocrinol (Copenh) 1986;113:593-97

4. Layman LC. Genetics of human hypogonadotropic hypogonadism. Am J Med Genet 1999;89:240-48

5. Hall JE. Physiologic and genetic insights into the pathophysiology and management of hypogonadotropic hypogonadism. Ann Endocrinol 1999; 60:93-101

6. Assouline S, Shevell MI, Zatorre RJ, et al. Children who can't smell the coffee: isolated congenital anosmia. J Child Neurol 1998;13:168-72

7. Jafek BW, Gordon AS, Moran DT, et al. Congenital anosmia. Ear Nose Throat J 1990;69:331-37

8. Leopold DA, Hornung DE, Schwob JE. Congenital lack of olfactory ability. Ann Otol Rhinol Laryngol 1992;101:229-36

9. Yousem DM, Geckle RJ, Bilker W, et al. MR evaluation of patients with congenital hyposmia or anosmia. AJR Am J Roentgenol 1996;166:439-43

10. Klingmüller D, Dewes W, Krahe T, et al. Magnetic resonance imaging of the brain in patients with anosmia and hypothalamic hypogonadism (Kallmann's syndrome). J Clin Endocrinol Metab 1987;65:581-84

11. Truwit CL, Barkovich AJ, Grumbach MM, et al. MR imaging of Kallmann syndrome, a genetic disorder of neuronal migration affecting the olfactory and genital systems. AJNR Am J Neuroradiol 1993;14:827-38

12. Doty RL, Bromley SM, Moberg PJ, et al. Laterality in human nasal chemoreception. In: Christman S, ed. Cerebral Asymmetries in Sensory and Perceptual Processing. Amsterdam, the Netherlands: North Holland Publishing; 1997:497-542

13. Abolmaali ND, Hietschold V, Vogi TJ, et al. MR evaluation in patients with isolated anosmia since birth or early childhood. AJNR Am J Neuroradiol 2002;23:157-63
14. Hummel T, Pietsch H, Kobal G. Kallmann's syndrome and chemosensory evoked potentials. Eur Arch Otorhinolaryngol 1991;248:311-12

15. Laska M, Distel H, Hudson R. Trigeminal perception of odorant quality in congenitally anosmic subjects. Chem Senses 1997;22:447-56

16. Hummel T. Assessment of intranasal trigeminal function. Int J Psychophysio 2000;36:147-55

17. Hummel T, Sekinger B, Wolf SR, et al. "Sniffin' sticks": olfactory performance assessed by the combined testing of odor identification, odor discrimination and olfactory threshold. Chem Senses 1997;22:39-52

18. Kobal G, Klimek L, Wolfensberger M, et al. Multi-center investigation of 1036 subjects using a standardized method for the assessment of olfactory function combining tests of odor identification, odor discrimination, and olfactory thresholds. Eur Arch Otorhinolaryngol 2000;257:205-11

19. Kobal G, Hummel T. Olfactory and intranasal trigeminal event-related potentials in anosmic patients. Laryngoscope 1998;108:1033-35

20. Rombaux P, Grandin C, Duprez T. How to measure olfactory bulb volume and olfactory sulcus depth? B-ENT 2009;5(suppl 13):53-60

21. Knorr JR, Ragland RL, Brown RS, et al. Kallmann syndrome: MR findings. AJNR Am J Neuroradiol 1993;14:845-51

22. Turetsky BI, Crutchley P, Walker J, et al. Depth of olfactory sulcus: a marker of early embryonic disruption in schizophrenia? Schizophr Res 2009;115:8-11

23. Hummel T, Damm M, Vent J, et al. Depth of olfactory sulcus and olfactory function. Brain Res 2003;975:85-89

24. Movshon JA, Van Sluyters RC. Visual neural development. Annu Rev Psychol 1981;32:477-522

25. Silverman MS, Clopton BM. Plasticity of binaural interaction. I. Effect of early auditory deprivation. J Neurophysiol 1977;40:1266-74

26. Webster DB, Webster M. Effects of neonatal conductive hearing loss on brain stem auditory nuclei. Ann Otol Rhinol Laryngol 1979;88:684-88

27. Van der Loos H, Woolsey TA. Somatosensory cortex: structural alterations following early injury to sense organs. Science 1973;179:395-98

28. Rombaux $\mathrm{P}$, Potier $\mathrm{H}$, Bertrand $\mathrm{B}$, et al. Olfactory bulb volume in patients with sinonasal disease. Am J Rhinol 2008;22:598-601 